\title{
OPORTUNIDADES E DESAFIOS PARA O DESENVOLVIMENTO DO AGROTURISMO NO MUNICÍPIO DE INHAMBANE EM MOÇAMBIQUE
}

\author{
Hélsio Amiro Motany de Albuquerque Azevedo ${ }^{1}$
}

\section{Resumo}

A agricultura, no município de Inhambane, é praticada por famílias localizadas em áreas rurais e a actividade turística é representada, maioritariamente, por investimento estrangeiro desconectado destas famílias. A realidade põe em questão o aspecto do desenvolvimento endógeno e contribui para a consolidação de perspectivas de cima para baixo, onde famílias e comunidades em geral se tornam "espectadoras" das transformações dos respectivos territórios sem contribuirem para o seu desenvolvimento, contrariando a filosofia da Economia Solidaria. Considerando a possibilidade de integrar a agricultura familiar ao sector do turismo, buscou-se, neste artigo, avaliar se estão criadas as condições para o desenvolvimento do agroturismo em Inhambane, pontuando-se as oportunidades existentes e desafios. Reconhecendo que grande parte dos estabelecimentos turísticos e residentes ainda importam produtos agrícolas frescos da África do Sul, da cidade de Maputo e do distrito de Chókwè, há uma necessidade de mudar esse paradigma comercial, fazendo com que esses produtos sejam produzidos nas zonas húmidas do município e consequentemente reduzir a dependência externa, fato que fortaleceria a produção doméstica, melhorando a renda dos produtores. A metodologia baseou-se nos métodos e técnicas existentes nas ciências sociais, em métodos mistos de pesquisa, pois o tema desenvolvido abrange diversas áreas do conhecimento, como é o caso, por exemplo, das áreas de turismo, agricultura e economia. Constatou-se que o município possui potencial agrícola localizado próximo às planícies e em áreas próximas às lagoas naturais e pequenos riachos que ali ocorrem e que existem potencialidades e possibilidade de integrar agricultura familiar e turismo, o que resultará em iniciativas de agroturismo; embora tenha sido observado que o potencial não é explorado para agregar mais renda aos produtores locais e consequentemente reduzir a dependência externa e fortalecer a produção doméstica de produtos agrícolas. Assim, conclui-se que há uma oportunidade de estabelecer conexões entre agricultura e turismo, pois é uma maneira das comunidades valorizarem sua cultura e o ambiente rural. Os desafios para a concretização estão relacionados a limitada infra-estrutura de apoio, pouco conhecimento da área hoteleira e limitações para realização da promoção da oferta. Uma das evidências do potencial encontrado é a gastronomia típica das comunidades rurais, o conhecimento local e a própria cultura. Contudo, o potencial agrícola das áreas rurais e a combinação com as características das comunidades rurais não são incorporadas à produção turística, abrindo-se a oportunidades para inserir a filosofia da economia solidária no processo de desenvolvimento agro-turístico.

Palavras-chave: Agroturismo, Desafios, Oportunidades, Inhambane.

\footnotetext{
1 Professor na Universidade Eduardo Mondlane, Escola Superior de Hotelaria e Turismo de Inhambane,
} Departamento de Turismo. Email: helazevedo@uem.mz. 


\title{
OPPORTUNITIES AND CHALLENGES FOR AGROTOURISM DEVELOPMENT IN THE MUNICIPALITY OF INHAMBANE IN MOZAMBIQUE
}

\begin{abstract}
The agriculture in the municipality of Inhambane is practiced by families located in rural areas and the tourist activity is mostly represented by foreign investment, which is disconnected from these families. The reality argues the issue of endogenous development and contributes for the consolidation of the top-down perspectives, where families and communities in general become "spectators" of the transformations of the respective territories without contributing for their development, contradicting the philosophy of the solidarity economy. Considering the possibility of the family farming integration to the tourism sector, this study aimed to assess whether the conditions for agro-tourism development in Inhambane are created, particularly for the existing opportunities and challenges. Acknowledging that a large part of the tourist establishments and residents still import fresh agricultural products from South Africa, city of Maputo and from Chókwè district, there is a need to change this commercial paradigm, through the production of these products in the wetlands of the municipality and consequently reduce the external dependence, fact that would strengthen domestic production and improve the income of the producers. This study was conducted under the research methods and techniques available in the social sciences, a mixed method was applied in regard of the developed theme which covers several areas of knowledge, and such is the case, for example, in the areas of tourism, agriculture and economy. The study revealed that the municipality has a great agricultural potential located close to lowlands and in areas close to natural lakes and small rivers that run there and that there are potentialities and possibilities to integrate family farming and tourism, which will result in agro-tourism initiatives; although it has been observed that the potential is not exploited to add more income to local producers and consequently reduce the external dependence and strengthen domestic production of agricultural products. However, the study concludes that there is an opportunity to establish connections between agriculture and tourism, because it is a form that communities could apply to value their culture and rural environment. The challenges for achieving it are related to limited supporting infrastructure, lack of knowledge in hospitality area and limitations for carrying out the promotion and offer. One of the identified potential evidences is the typical gastronomy of the rural communities, the local knowledge and their own culture. However, the agricultural potential of the rural areas and the combination with the characteristics of the rural communities are not incorporated in tourist production, opening up opportunities to integrate the philosophy of solidarity economy in the process of agro-tourism development.
\end{abstract}

Keywords: Agro-tourism, Challenges, Opportunities, Inhambane. 


\section{OPPORTUNITÉS ET DÉFIS POUR LE DÉVELOPPEMENT DE L'AGRI TOURISME DANS LA MUNICIPALITÉ D'INHAMBANE AU MOZAMBIQUE}

\section{Résumé}

L'agriculture, dans la mairie d'Inhambane est pratiquée par des familles vivant dans les zones rurales et l'activité touristique est représentée, en grande partie, par l'investissement étranger déconnecté des familles. La réalité pose en question l'aspect du développement endogène et contribue pour la consolidation de perspectives du plus haut vers le bas, où les familles et communautés en générale, deviennent des 'spectateurs' des transformations de ses respectives territoires sans contribuer pour son développement, fait qui est le contraire à la philosophie de l'économie solidaire. Considérant la possibilité d'intégrer l'agriculture familiale au secteur du tourisme, on cherche, dans cet article, à évaluer les conditions pour le développement de l'agrotourisme à Inhambane, prenant compte les opportunités existantes ainsi que ses défis. Reconnaissant que la majorité des établissements touristiques ainsi que des résidences font encore l'importation des frais produits agricoles de l'Afrique du Sud, de la ville de Maputo ainsi que du district de Chókwè, il y a un besoin de changer ce paradigme commercial, faisant en sorte que ces produits soient cultivés dans les zones agricoles de la mairie et réduire, par conséquent, la dépendance externe, ce que favoriserait la production locale, améliorant le revenu. La méthodologie s'est basé des méthodes et techniques existantes dans les sciences sociales, méthodes mixtes de recherche, car ce thème touche divers domaines de connaissance, tel que le tourisme, l'agriculture et l'économie. Il a été constaté que la mairie a un potentiel agricole et que dans les espaces près de lagunes naturels et petites rivières y coulant, il y a de potentialités et possibilités d'intégrer l'agriculture familiale et tourisme, que ce découlerait en initiatives d'agrotourisme; malgré le fait qu'il y ait été observé que le potentiel n'est pas exploité pour donner du revenu à partir de produits locaux et par conséquent réduire la dépendance externe et favoriser la production locale de produits agricoles. Ceci étant, il se conclut qu'il y a une opportunité de s'établir des connexions entre l'agriculture et le tourisme, car c'est une manière de faire en sorte que les communautés valorisent leur culture et l'environnement rural. Les défis pour la concrétisation sont liés à la limitation des infrastructures d'appui, peu de connaissance dans le domaine de l'hôtellerie et limitations pour la promotion de l'offre. L'une des évidences du potentiel rencontré, c'est la gastronomie typique des communautés rurales, la connaissance locale ainsi que la culture. Cependant, le potentiel agricole des zones rurales et la combinaison avec les caractéristiques des communautés rurales ne sont pas incorporés à la production touristique, s'ouvrant aux opportunités pour insérer la philosophie de l'économie solidaire dans le processus de développement agrotouristique.

Mots clés: Agrotourisme, Défis, Opportunités, Inhambane. 


\section{INTRODUÇÃO}

O município de Inhambane (MI) em Moçambique, pelas suas características físicas e geográficas, apresenta condições favoráveis para o desenvolvimento do turismo e da agricultura (Azevedo \& Campos, 2016). Estas duas actividades são praticadas de forma individualizada sem estabelecerem-se acções conjuntas que poderão resultar no agroturismo, uma tipologia de actividade que valoriza o trabalho dos agricultores a partir das suas práticas, com foco na colheita e na gastronomia local.

No MI, a agricultura é praticada, de grosso modo, pelos agregados familiares localizados nas zonas rurais e o turismo é mais representado pelo investimento estrangeiro e está desvinculado dos agregados familiares. Este aspecto põe em causa a vertente de desenvolvimento endógeno e contribui na solidificação de perspectivas top down, onde os agregados familiares e as comunidades em geral tornam-se passíveis "telespectadores" das transformações das respectivas zonas e sem muito a fazer para o desenvolvimento das mesmas.

Com vista a proporcionar mais protagonismo aos produtores familiares, organizados em associações, no ano 2014, o MI foi alvo de um projecto de cooperação universitária, entre a Escola Superior de Hotelaria e Turismo de Inhambane (ESHTI) - Universidade Eduardo Mondlane em Moçambique e o Instituto de Estudos Socioambientais - Universidade Federal de Goiás no Brasil, denominado "Sementes crioulas, quintais agro-ecológicos e cooperação popular: troca de saberes e experiências de economia criativa do cerrado brasileiro as savanas em Inhambane/Moçambique". Os resultados publicados referentes a pesquisa "indicam que há potencial agrícola no município e que o mesmo está localizado junto às baixas e nas áreas próximas às lagoas naturais e pequenos riachos que ai ocorrem"(Azevedo \& Campos, 2016, p. 48).

Nesse contexto, há potencialidades e possibilidade de integrar a agricultura familiar e o turismo, que consequentemente resulta no turismo rural. Uma das evidências do potencial para o turismo rural é a gastronomia típica das comunidades rurais, o saber local e a cultura em si. Entretanto, o potencial agrícola e turístico que as zonas rurais do município possuem e a conjugar com as características das comunidades rurais podem facilmente possibilitar a integração das comunidades no desenvolvimento do turismo, uma vez que estas não estão incorporadas na produção do turismo de forma directa. 
Assim, o presente artigo pretende avaliar se estão criadas as condições para o desenvolvimento do agroturismo em Inhambane, pontuando as oportunidades e os desafios existentes. A metodologia baseou-se nos métodos e técnicas existentes nas ciências sociais, em métodos mistos de pesquisa, pois o tema desenvolvido abrange diversas áreas do conhecimento, como é o caso, por exemplo, das áreas de turismo, agricultura e economia. Realizou-se questionários e entrevistas dirigidas as associações e seus membros para avaliar as condições de implantação de iniciativas de agroturismo, incluindo contactos com lideranças/gestores da área agrícola e do turismo.

\section{ROTEIRO METODOLÓGICO}

A revisão bibliográfica consistiu na identificação, selecção, análise de livros, monografias, dissertações, teses e artigos científicos relacionados com o tema, com vista a perceber os conceitos básicos que serviram de sustentação ao trabalho. Desta feita, a revisão bibliográfica propiciou a familiarização com os termos chave e a elaboração dos instrumentos para uso no campo e para identificar as melhores técnicas de recolha de dados. Igualmente, através de trabalhos de campo com entrevistas, aplicação de questionários, observação dos espaços de cultivo, realizados com as associações de camponeses/as pertencentes à União de Camponeses da cidade de Inhambane (UCCI) no ano de 2018, experiências com uma associação na indução a actividades turística e consulta de dados junto ao Conselho Municipal da Cidade de Inhambane (CMCI) foram levantadas informações secundárias relevantes. Em relação aos questionários, importa frisar que estes foram dirigidos aos vinte e três Presidentes das associações e trezentos e sessenta e três membros de um total de quatrocentos e noventa e oito membros para avaliar às condições para a implantação de iniciativas de agroturismo nas associações existentes. Para o efeito, usou-se a plataforma Google forms para inserção e processamento da informação colectada, fato que permitiu a elaboração de gráficos. Importa referir que os dados secundários utilizados na apresentação de resultados são parte dos resultados do projecto Agricultura familiar Agricultura Familiar, Turismo e Desenvolvimento Rural: Ligação e Integração do Rural-Urbano no Município de Inhambane, 2018, desenvolvido pela ESHTI e pela Faculdade de Agronomia (resultados gerais podem ser vistos no site do projecto: https://projecto284eshti.wixsite.com/paftdr/publicacoes-do-grupo). Este projecto foi uma continuidade do projecto "Sementes crioulas, quintais agro-ecológicos e cooperação 
popular: troca de saberes e experiências de economia criativa do cerrado brasileiro as savanas em Inhambane/Moçambique".

Para além da pesquisa, o projecto privilegiou a extensão universitária como forma de contribuir para a melhora na produção, comercialização e gestão de unidades agrícolas. Para o efeito, foram realizados workshops com os gestores e parte dos membros das associações no sentido de abordar temáticas relacionadas com o associativismo, economia solidaria, cooperativismo, liderança, tecnologias de comunicação na comercialização, entre outros temas. Vale destacar que se trabalhou com às associações por estas serem mais expressivas e a maior parte mostrarem-se organizadas no processo de produção agrícola numa lógica alicerçada aos princípios da Economia Solidária.

\section{Economia Solidária e Agroturismo}

O conceito de Economia Solidária (ES) ainda não reúne consenso no meio académico, principalmente pela abordagem de rotura com o sistema económico hegemónico instituído em muitos países.

De acordo com Singer (2002), a ES nasce como resposta ao empobrecimento maciço dos trabalhadores europeus, a partir do desenvolvimento do sistema fabril, do crescimento dos centros urbanos e das sucessivas crises econômicas do sistema capitalista.

Azevedo et al. (2016) entendem a ES como um movimento e uma contra racionalidade ao modo de produção e organização econômica vigente em escala global. Para Mascarenhas (2012, p.142)

o termo Economia Solidária (ES) é utilizado para designar, genericamente, experiências econômicas que buscam gerar trabalho e renda para seus participantes a partir de modos de organização distintos dos utilizados em empresas tradicionais. Privilegia-se nas experiências de economia solidária a atuação autogestionária ou de base comunitária e democrática. São experiências pautadas em ideais de solidariedade, ajuda-mútua, associativismo, cooperação e igualdade nos planos econômico e político.

Barros e Oliveira (2019) entendem que 
o desenvolvimento da economia solidária, objetivada especialmente pela construção de cooperativas e associações de trabalhadores, relaciona-se ao contexto de crise econômica ampla que afeta não só as diferentes economias do mundo, mas também as bases do mecanismo histórico de regulação das sociedades na modernidade, marcadas pela sinergia entre estado e mercado. Ela tem por vocação combinar uma dimensão comunitária, mais tradicional, com uma dimensão pública, mais moderna em sua acção.

Entende-se assim, nas abordagens descritas acima, que a ES busca o empoderamento dos grupos sociais que não se inserem na lógica do mercado liberal, mas que tenham capacidade de produção, de forma associada, de bens e serviços úteis ao mercado.

França Filho (2007) sugere pelo menos cinco possibilidades de "entrada" no universo da economia solidária:

1) abordá-la como discussão conceitual, buscando entender as suas diferentes nuances e possibilidades teóricas;

2) abordá-la segundo uma perspectiva contextual, ou seja, problematizar como a ES se manifesta em contextos sociais específicos, e relacioná-la com outros fenômenos sociais, tais como o sistema capitalista, a crise do trabalho e do trabalhador na contemporaneidade, os problemas de exclusão e desigualdade social, as formas de combate à pobreza e as lutas por desenvolvimento local e sustentável, entre outros;

3) examinar a ES como estudo de caso, buscando compreender as suas práticas organizacionais e processos gerenciais, como se constituem e como são operacionalizadas no seu cotidiano;

4) abordar a ES como metodologia de intervenção, analisando-a na perspectiva de formulação e multiplicação de tecnologias sociais para a geração de trabalho e renda, produção sustentável e desenvolvimento local;

5) abordá-la como política pública, uma vez que esta tem sido, no caso brasileiro, um novo campo de prática da ES, a partir da formulação e implementação de políticas de geração de trabalho e renda e inclusão produtiva, principalmente.

No presente trabalho, o foco será dado ao ponto 3 tangenciando os demais. Busca-se compreender como o agroturismo se constitui uma possibilidade para incrementar o leque de actividades que as associações agrícolas no MI podem realizar, possibilitando assim, a agregação de renda aos membros, valorização das práticas agrícolas e sociais e uma rotura ao modelo instituído para o desenvolvimento do turismo neste município que segundo Gota (2018) está alicerçado ao capital internacional, com fraco envolvimento das comunidades/associações/cooperativas.

A agricultura, principal actividade económica de alguns países, como Moçambique e Brasil por exemplo, é desenvolvida por diferentes tipos de intervenientes, a destacar as grandes corporações, associações/cooperativas e famílias/individuo, originando diferentes tipos de classificação da agricultura. Neste trabalho o foco é dado a agricultura familiar que é uma forma de produção oposta a produção moderna, exercida pelas grandes corporações em áreas muito extensas com objectivos comercias, principalmente, de monoculturas. 
Pretende-se, essencialmente, avaliar às condições da promoção do agroturismo em propriedades rurais que tem como objectivo primordial o garante do auto-sustento do agregado familiar/membros sem necessariamente subjugar a geração de renda a partir desta produção (Gota, 2018).

Segundo Portuguez (2017, p. 60) o agroturismo é "entendido como a modalidade de turismo em espaço rural praticada dentro das propriedades, de modo que o turista e/ou excursionista entra, mesmo que por um curto período de tempo, em contato com a atmosfera da vida na fazenda, integrando-se de alguma forma aos hábitos locais”.

Para Guzatti (2003, p.17)

[...] o agroturismo é ... uma ferramenta importante na construção de um desenvolvimento sustentável do espaço rural. Isso porque seu principal produto é o(a) agricultor (a), seu modo de vida, sua cultura e tradições, seu trabalho e o meio ambiente onde vive, justificando-se o interesse da atividade turística em manter e valorizar estes "bens". Assim, são indicadas inúmeras possibilidades para os agricultores familiares nesta atividade: a produção de alimentos saudáveis, o processamento destes alimentos em pequenas indústrias, a preservação da natureza e da cultura, a prestação de serviço, o lazer, dentre tantas outras atividades que se multiplicam no espaço rural e consagram-se como novas oportunidades de geração de renda e de trabalho.

Barbieri (2010) e Tew e Barbieri (2012) citados por Fantini et al. (2018) explicam que o agroturismo é geralmente considerado como o conjunto de atividades realizadas em um estabelecimento rural, permitindo a integração de renda ou do valor agregado agrícola, isto é, é uma das diferentes formas de diversificação das explorações agrícolas, e inclui a compra direta de produtos no local, atividades e eventos de lazer, participação em negócios da unidade de produção, refeições e hospitalidade.

Entende-se que a comercialização no agroturismo, geralmente, é directa, sem necessariamente estar vinculada às empresas turísticas, requerendo o preparo dos gestores destas propriedades para atender o fluxo de visitantes. Este aspecto é secundado por Esposti (2006) citado por Fantini et al. (2018, p. 523) ao explicar que pelo

fato de o agroturismo permanecer uma realidade interna ao mundo agrícola, de fato, nunca deve fazer-nos esquecer do outro elemento fundamental, que é um negócio orientado ao mercado turístico. Em relação a esse mercado, o agroturismo hoje precisa concentrar os esforços em dois fatores cruciais: ter estratégias de comunicação, promoção e organização, e oferecer uma gestão integrada da oferta. 
Entende-se que apesar deste modelo de produção estar mais próximo da essência da ES, não se deve negligenciar a organização para o negócio, fato que requer a participação de diferentes actores, exemplifica-se a Universidade através da pesquisa e extensão dos seus diferentes cursos, no apoio aos grupos que tem a sua base de sustento em principio da ES.

Vale destacar que as iniciativas de agroturismo, na sua essência, devem estar associadas às práticas produtivas ecológicas, de base natural, agregando maior qualidade dos serviços e produtos a oferecer, distanciando-se de práticas que destroem os solos, o ar e água, pelo uso intensivo de químicos e agro-tóxicos, práticas associadas a produção comercial fomentada pelas grandes corporações no sistema capitalista.

Importa frisar que o agroturismo eleva a auto-estima da população e possibilita uma compreensão pelo próprio agricultor de que seu modo de vida é valorizado por outras pessoas justamente pelos elementos que são considerados tradicionais e que são desvalorizados pelo discurso da sociedade moderna (Zandonadi e Freire, 2016).

\section{RESULTADOS}

\section{Localização e características geográficas do Município de Inhambane}

O MI situa-se na região Sul de Moçambique, na parte sudeste da província de Inhambane, a aproximadamente $460 \mathrm{~km}$ ao norte da cidade de Maputo, capital moçambicana; a $260 \mathrm{~km}$ ao norte de Xai-Xai e a $740 \mathrm{~km}$ ao sul da cidade da Beira (Bilério, 2007). De acordo com Nhantumbo (2007, p. 16), o município

Encontra-se localizado na região sul de Moçambique e ocupa uma parte da zona costeira da província de Inhambane. Situa-se entre as latitudes 23.45'50" (Península de Inhambane) e 23.58'15" (Rio Guiúa) Sul, e as longitudes 35.22'12" (Ponta Mondela) e 35.33'20" (Cabo Inhambane) Este, cobrindo uma parte continental e duas ilhas.

Esse município é a capital da província de Inhambane e segundo o Instituto Nacional de Estatística (INE, 2010) ocupa uma superfície de $195 \mathrm{~km}^{2}$, que perfaz uma área de $0.3 \%$ do território total da província, limitando-se ao norte pela Baía de Inhambane, no Oceano Índico; ao sul, pelo Distrito de Jangamo, pelo rio Guiúa; ao leste, pelo Oceano Índico e ao oeste, pela Baía de Inhambane, município da Maxixe (conforme mostra o Mapa 1). 
Mapa 1. Localização e limites do município de Inhambane

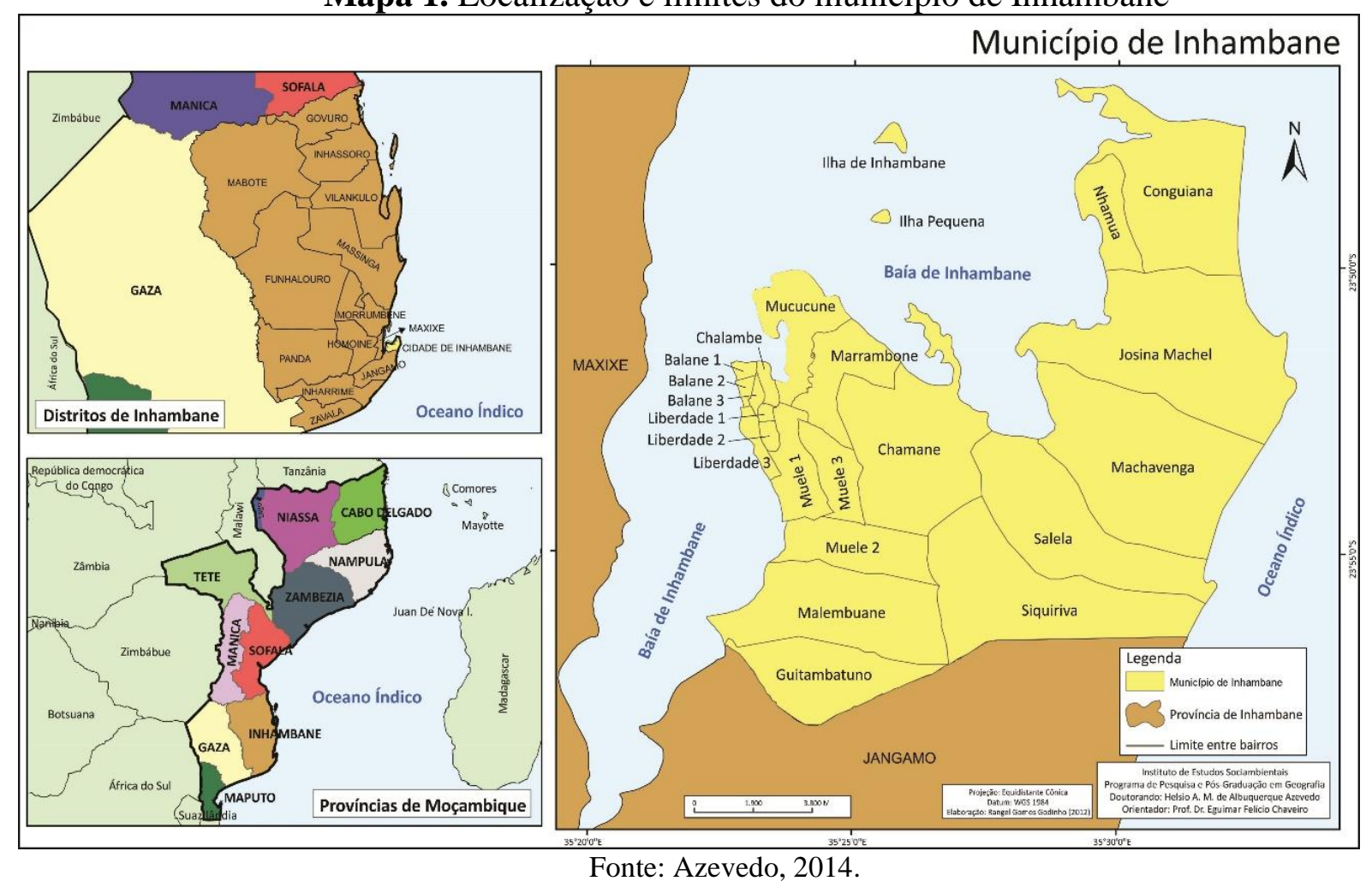

Segundo o Instituto Nacional de Planeamento Físico (INPF, 1991, p. 25), o clima que se verifica no município de Inhambane é "tropical húmido e a temperatura média anual varia entre os $20,3^{\circ} \mathrm{C}$ e $26,9^{\circ} \mathrm{C}$, sendo que os valores mínimos registram-se em julho e os máximos em janeiro". Nhantumbo (2007, p. 19) salienta que "o clima do município de Inhambane é tropical húmido ao longo da costa, com temperaturas médias que variam entre $25^{\circ} \mathrm{C}$ na estação quente e húmida a $20^{\circ} \mathrm{C}$ na estação fresca e seca". O mesmo autor refere que os ventos chegam a atingir 5 a $8 \mathrm{~km} / \mathrm{h}$ de máxima, exceto quando há ocorrência de eventos críticos, como ciclones, elevando essa velocidade para ventos que variam entre 75 e $140 \mathrm{~km} / \mathrm{h}$.

As condições climáticas do município favorecem a prática de atividades agrícolas e turísticas diversas, principalmente ao turismo de sol e praia (AZEVEDO, 2014).

\section{Potencial para o Agroturismo no MI}

\section{a)Produtos oferecidos e organização}

Em termos de resultados, constata-se que há potencial agrícola no município e este possui áreas, principalmente às zonas com baixas, com solos férteis. De igual modo existem áreas propícias para produção agroecológica localizadas próximas às lagoas naturais e pequenos 
riachos que ai ocorrem, conforme ilustra a figura 1. Esta produção é dinamizada, na sua maioria, por associações que integram várias famílias. Há, igualmente, individuais e empresas agrícolas, com menos expressão.

A vegetação na área circundante às associações é pouco densa, criando uma paisagem verde. Nas áreas cultivadas, a vegetação predominante é maioritariamente composta por culturas como milho, cana-de-açúcar, amendoim, folha de batata-doce, folha de abobora, mandioqueira, folha de feijão nhemba, couve, cebolinha, cebola, alface, beterraba, piri-piri (Figura 2).

As características físicas e a diversidade ilustrada na figura 2, possibilita a existência de várias pessoas e associações agrícolas que têm na agricultura a sua base de sustento.

Figura 1. Mapa de uso do solo

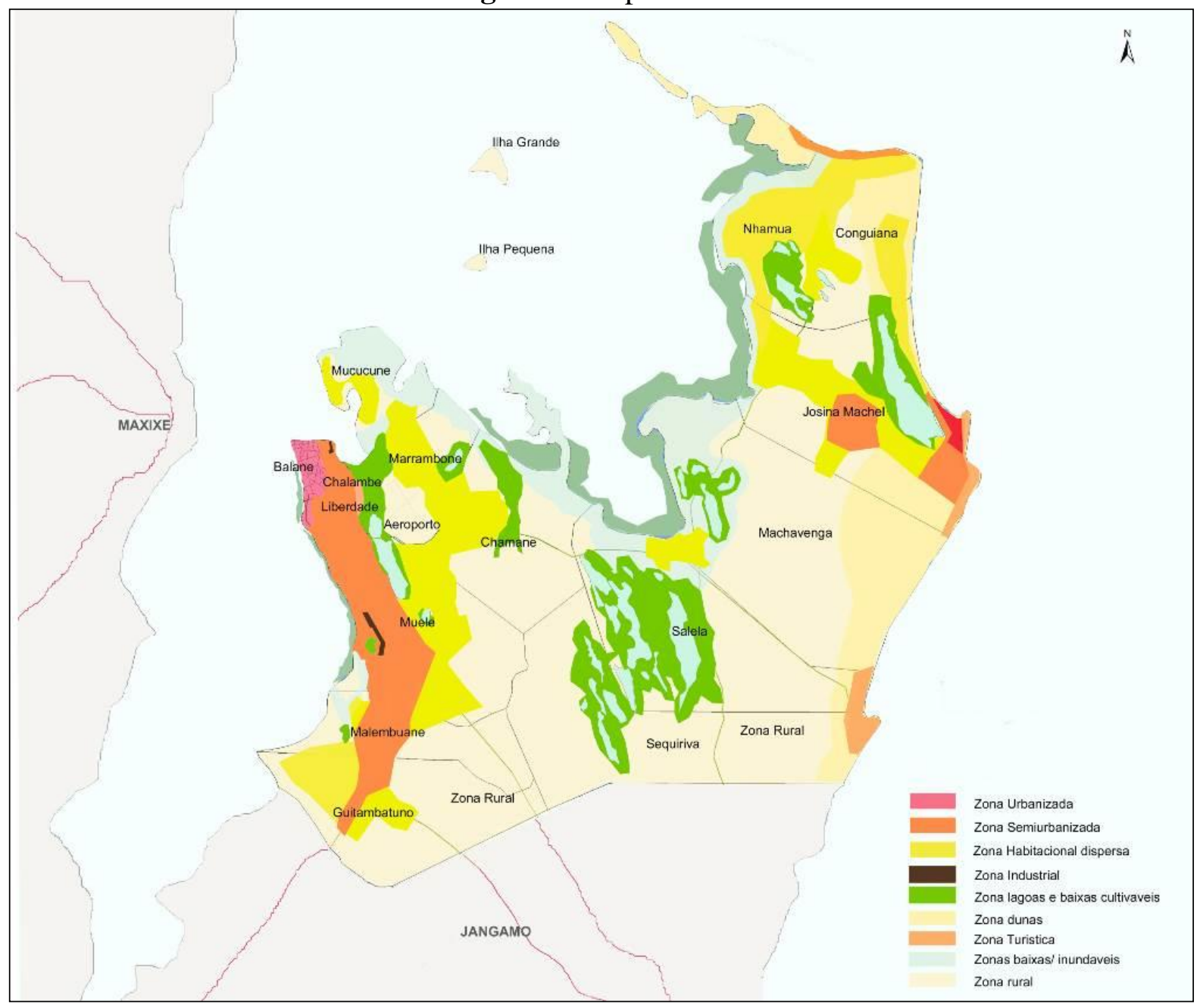


Figura 2: Culturas predominantes nas associações agrícolas no MI: A) milho,

B) Bananeira C) Alface, Cebolinha, Bananeira e Coqueiro) D) Abóbora,

E) Capim e Folha de batata-doce e F) Ananás.
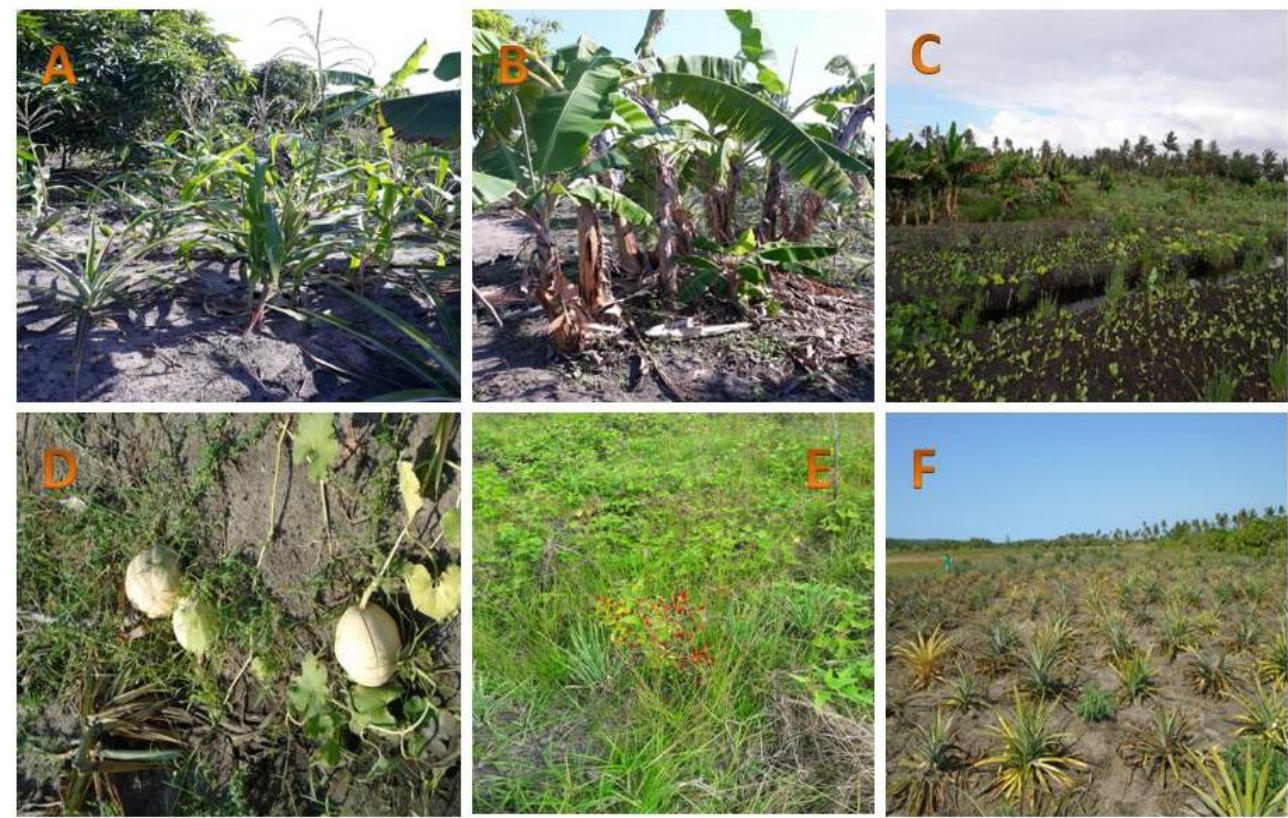

Fonte: Salehe (2018)

As figuras 1 e 2 mostram que há potencial e que o mesmo está disperso pelo município. Estas baixas abrigam machambas individuais, associações e empresas agrícolas. As associações possuem áreas de cultivo com dimensões variadas, sendo que umas são mais antigas e experientes que outras no processo de produção, conforme se apresenta no quadro 1.

Quadro 1. Associações agrícolas do MI

\begin{tabular}{|c|c|c|c|c|c|c|c|}
\hline $\mathbf{N}^{0}$ & Associação/Ano de Criação & Bairro & $\begin{array}{l}\text { Ano de } \\
\text { Criação }\end{array}$ & Legalização & $\begin{array}{c}\text { Membros } \\
\text { Total }\end{array}$ & Registados & $\begin{array}{c}\text { Nivel de } \\
\text { Execução (\%) }\end{array}$ \\
\hline 1 & 7 de Abril & Siquiriva & 2003 & Sim & 16 & 16 & 100 \\
\hline 2 & 24 de Julho & Siquiriva & 2008 & Não & 11 & 11 & 100 \\
\hline 3 & Vukane & Salela & 2015 & Não & 29 & 29 & 100 \\
\hline 4 & 15 de Outumbro & Salela & 2013 & Não & 16 & 11 & 69 \\
\hline 5 & Bakula & Chamane & 2017 & Não & 23 & 16 & 70 \\
\hline 6 & Kuvuneca & Chamane & 2006 & Não & 40 & 21 & 53 \\
\hline 7 & Zonas Verdes & Muele 3 e Guitambatuno & 1996 & Sim & 18 & 18 & 100 \\
\hline 8 & 4 de Outubro & Guitambatuno & 2007 & Não & 16 & 13 & 81 \\
\hline 9 & 7 de Setembro & Muele 3 & 2008 & Não & 9 & 9 & 100 \\
\hline 10 & Katalela & Muele 3 & 2012 & Sim & 24 & 4 & 17 \\
\hline 11 & Graça Machel & Muele 3 & 2016 & Não & 13 & 13 & 100 \\
\hline 12 & RIL & Muele 1 & 2016 & Não & 52 & 39 & 75 \\
\hline 13 & 3 de Fevereiro & Muele 1 & 2012 & Sim & 19 & 9 & 47 \\
\hline 14 & 25 de Junho & Muele 1 & 1988 & Sim & 21 & 15 & 71 \\
\hline 15 & Irmãos Unidos de Guilongue & Muele 3 & 2017 & Não & 28 & 23 & 82 \\
\hline 16 & A hirimene & Liberdade 2 & 2015 & Não & 14 & 14 & 100 \\
\hline 17 & 8 de Março & Chalambe 2 & 2010 & Não & 19 & 19 & 100 \\
\hline 18 & Ngungulu & Malembuane & 2012 & Não & 26 & 26 & 100 \\
\hline 19 & Marrambone & Marrambone & 1997 & Não & 27 & 25 & 93 \\
\hline 20 & Conguiana & Conguiana & 1989 & Sim & 10 & 10 & 100 \\
\hline 21 & 1 de Maio & Nhamua & 2014 & Não & 6 & 6 & 100 \\
\hline 22 & Tsembeca & Josina Machel & 2017 & Não & 12 & 0 & 0 \\
\hline 23 & Pembane & Conguiana & 2017 & Não & 49 & 9 & 18 \\
\hline \multicolumn{5}{|c|}{ TOTAL } & 498 & 356 & 71 \\
\hline
\end{tabular}

Fonte: Base de dados do Projecto Agricultura familiar Agricultura Familiar, Turismo e Desenvolvimento Rural: Ligação e Integração do Rural-Urbano no Município de Inhambane, 2018. 
Observa-se, no quadro 1, que parte da população do MI pratica e vive da agricultura, visto que, maior parte dos produtores são encarregados de sustentar suas famílias que em média integram mais de 5 agregados. Igualmente, observa-se que parte destas associações não estão legalizadas, apesar de estarem a operar a mais de três anos. Entre os factores descritos para a não regularização destaca-se a falta do conhecimento do processo de legalização e as limitações financeiras para cobrir as despesas do processo. Em termos de actividades, 99\% dedica-se a agricultura e uma única associação diversifica a produção com a prática da pecuária, apicultura e recepção de excursionistas. Todas estas associações congregadas formam a Associação de Camponeses da Cidade de Inhambane (UCCI). A UCCI integra a União Nacional dos Camponeses (UNAC), movimento que representa o setor familiar de camponeses de Moçambique. A UNAC (2015) possui uma visão, em seu manifesto, de trabalhar com a agroecologia.

\section{b) Formação dos Membros}

Os membros das associações, em termos gerais, possuem baixas qualificações escolares, conforme ilustra a figura 3.

Figura 3. Qualificações académicas dos membros das Associações agrícolas do MI

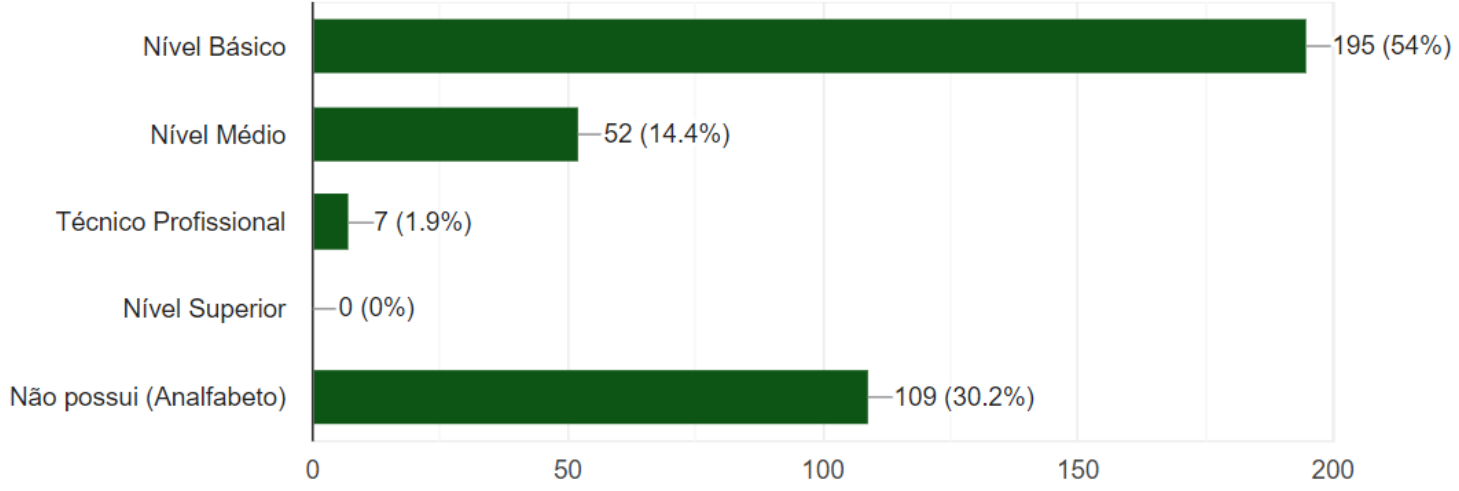

Fonte: Base de dados do Projecto Agricultura familiar Agricultura Familiar, Turismo e Desenvolvimento Rural: Ligação e Integração do Rural-Urbano no Município de Inhambane, 2018.

O grande número de analfabetos, conforme descrito na figura 3, é um aspecto que merece destaque uma vez que este número de pessoas terá limitações para poder realizar pesquisas para melhorar o processo de produção e comercialização dos produtos e serviços de agroturismo. Essa situação limita a integração destes em acções formativas de curta duração com recurso a manuais, visto que, para além da oralidade há necessidade de sistematização de 
conteúdos destes eventos. Um plano de formação dos membros nos níveis profissional e superior, em áreas essências mostra-se relevante.

\section{c)Infraestrutura}

As associações agrícolas apresentam potencialidade para a prática de turismo rural mas para se poder oferecer essa actividade há toda uma necessidade de se criarem condições com vista a trazer e instalar os turistas de modo seguro e satisfatório. Um dos elementos que compõe essas condições é a infra-estrutura básica. O mapa 2 apresenta as infra-estruturas básicas existentes nas associações agrícolas do MI.

Mapa 2. Infraestrutura básica existente nas associações Agrícolas

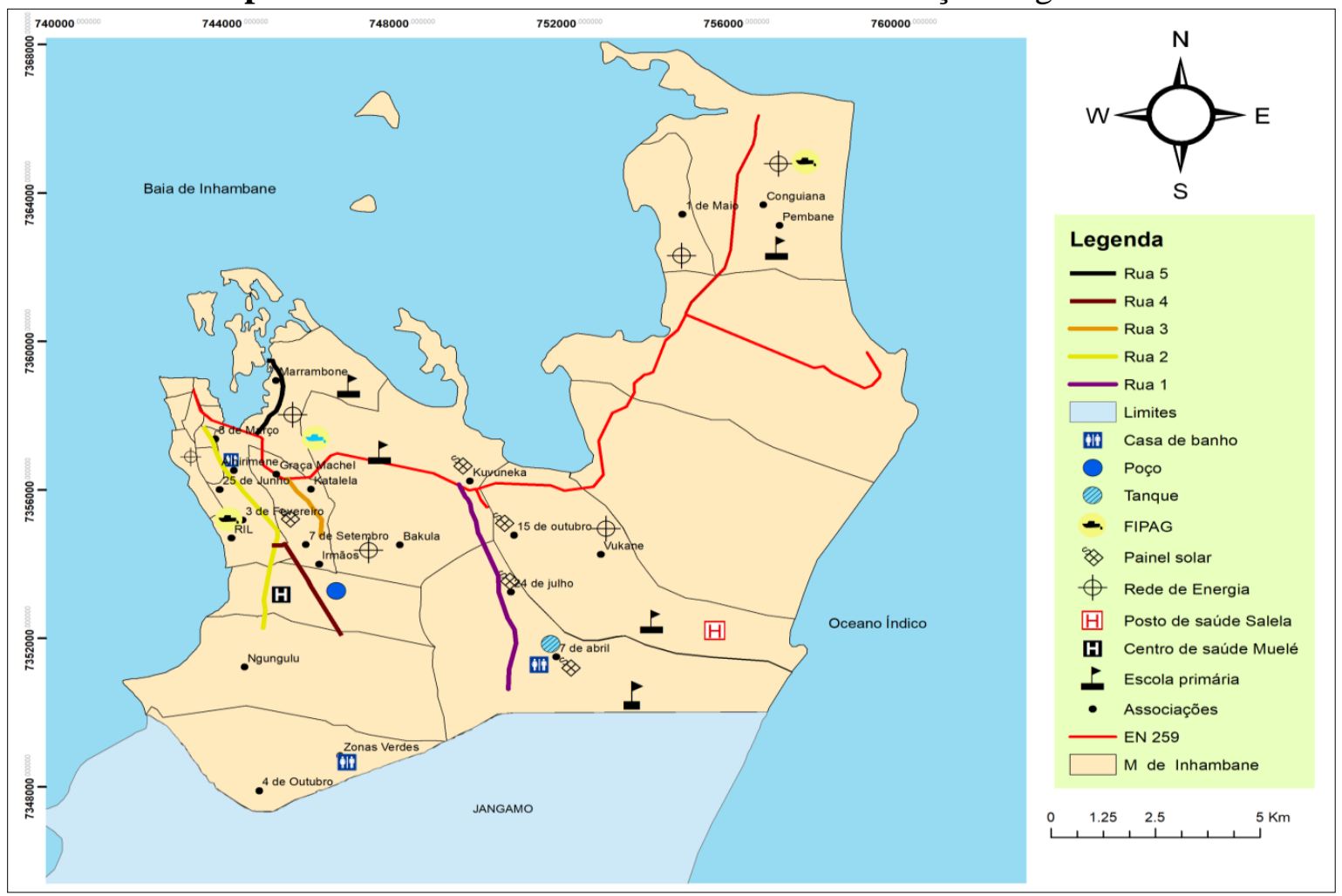

Fonte: Mtitu (2018)

Os subsistemas que compõem este sistema de infra-estrutura foram avaliados da seguinte forma, segundo Mtitu (2018): 
Quadro 2. Avaliação da infra-estrutura para apoio ao serviço das associações no MI

\begin{tabular}{|c|c|c|}
\hline Sub-sistema & Situação & Observações \\
\hline Água & $\begin{array}{l}\text { As associações agrícolas de MI possuem um sistema de } \\
\text { fornecimento de água não satisfatório visto que este } \\
\text { não atende aos padrões desejáveis como apresentado } \\
\text { por Beni (2002) ao explicar que para a sobrevivência } \\
\text { humana o ser humano necessita de água de boa } \\
\text { qualidade e em quantidade suficiente para as suas } \\
\text { necessidades, não só para a protecção à saúde, como } \\
\text { para seu desenvolvimento económico, social e cultural. } \\
\text { O mesmo autor salienta que o padrão que se deseja } \\
\text { atingir é o abastecimento de } 80 \% \text { da população com } \\
\text { água tratada, na proporção de } 250 \text { litros diários por } \\
\text { habitante, o que não se verifica nas associações } \\
\text { agrícolas do MI pois o sistema de fornecimento de água } \\
\text { existente serve a menor parte e com grandes } \\
\text { deficiências. Salientar que a qualidade e a quantidade } \\
\text { de água fornecida não é desejável pois a água dos } \\
\text { poços, furos e valas que ajudam os membros das } \\
\text { associações para fazer face a escassez deste líquido } \\
\text { para poderem suprir as necessidades básicas é salobra. } \\
\text { Referir que há acessibilidade da água para a irrigação } \\
\text { dos produtos nas machambas o que é um aspecto } \\
\text { positivo e observável para maioria das associações. }\end{array}$ & $\begin{array}{l}\text { Apesar dos representantes das } \\
\text { associações afirmarem que } \\
\text { associações se beneficiarem com } \\
\text { os meios alternativos de } \\
\text { fornecimento de água, a } \\
\text { insatisfação é notória por parte dos } \\
\text { mesmos que avaliam como } \\
\text { razoável o sistema de fornecimento } \\
\text { de água. Este fato demonstra que } \\
\text { há necessidade de se melhorar o } \\
\text { fornecimento de água, em termos } \\
\text { de quantidade e qualidade, para } \\
\text { promover o turismo rural nas } \\
\text { associações. }\end{array}$ \\
\hline Energia & $\begin{array}{l}\text { O sistema de distribuição de energia eléctrica ainda é } \\
\text { insatisfatório para maior parte das associações uma vez } \\
\text { que este sistema não possui a capacidade para servir a } \\
\text { todas. Para Beni (2002), os padrões desejáveis de } \\
\text { distribuição de energia para fins rurais em toda a região } \\
\text { de alta densidade demográfica; iluminação em todas as } \\
\text { ruas com mais de } 50 \% \text { dos lotes ocupados, das vias } \\
\text { comerciais e de grande tráfego, e das vias de acesso aos } \\
\text { equipamentos sociais e todos os espaços de oferta de } \\
\text { turismo rural devem possuir fonte energética. O } \\
\text { indicador não se observa nas associações agrícolas do } \\
\text { MI, apesar de existirem os meios alternativos de } \\
\text { sistema energético como painel solar. Este ainda não } \\
\text { satisfaz as necessidades de todos os membros das } \\
\text { associações porque a maioria não tem capacidade } \\
\text { financeira de adquirir. No concernente à iluminação } \\
\text { nas vias públicas e nas associações agrícolas é de } \\
\text { referir que a situação actual não é boa porque a maior } \\
\text { parte deste não se encontra iluminado, observando-se } \\
\text { uma iluminação de fraca qualidade nos locais de } \\
\text { ocorrência destas como é o caso das associações de } \\
\text { Marrambone, } 8 \text { de Março e A hirimene que se encontra } \\
\text { perto de centro da cidade. }\end{array}$ & $\begin{array}{l}\text { Portanto há necessidade de se } \\
\text { melhorar o sistema de distribuição } \\
\text { de energia eléctrica para que } \\
\text { cumpra com o padrão desejado, o } \\
\text { que facilitará a promoção do } \\
\text { turismo rural nas associações e } \\
\text { garantirá a conservação dos } \\
\text { alimentos. }\end{array}$ \\
\hline Comunicação & $\begin{array}{l}\text { Apesar dos membros das associações se mostrarem } \\
\text { satisfeitos com o sistema de comunicação é de referir } \\
\text { que este cobre maior parte das associações através dos } \\
\text { serviços de telefonia móvel. A comunicação possibilita } \\
\text { às populações residentes e flutuantes (como por } \\
\text { exemplo turistas) um rápido contacto com os serviços } \\
\text { de saúde e de segurança pública em caso de } \\
\text { necessidade (Beni, 2002). }\end{array}$ & $\begin{array}{l}\text { De referir que os serviços de rádio } \\
\text { e televisão ainda não são } \\
\text { satisfatórios para maior parte das } \\
\text { associações pelo fato de as } \\
\text { mesmas serem localizadas nos } \\
\text { bairros rurais do município o que } \\
\text { dificulta a captação dos canais. }\end{array}$ \\
\hline $\begin{array}{c}\text { Saneamento } \\
\text { do Meio }\end{array}$ & $\begin{array}{l}\text { O saneamento do meio nas associações tem-se } \\
\text { mostrado crítico se tiver-se em conta que todos os } \\
\text { subsistemas (lixo e casa de banho) que compõem este }\end{array}$ & $\begin{array}{l}\text { Apesar das associações como } 3 \text { de } \\
\text { Fevereiro, } 8 \text { de Março e A } \\
\text { Hirimene terem um sistema de }\end{array}$ \\
\hline
\end{tabular}




\begin{tabular}{|c|c|c|}
\hline & $\begin{array}{l}\text { sistema encontram-se com inúmeros problemas fato } \\
\text { que poderá, a curto prazo, manchar, se não colmatado, } \\
\text { a imagem destes destinos. Como refere Azevedo } \\
\text { (2006), a má qualidade de apresentação de um destino } \\
\text { pode, até certo ponto, repelir a demanda e } \\
\text { investimentos, visto que, ninguém se sente atraído por } \\
\text { lugares imundos para os visitar. Salientar que a } \\
\text { inexistência de saneamento básico pode originar } \\
\text { problemas de saúde (doenças como a cólera por } \\
\text { exemplo) aos visitantes e aos residentes de } \\
\text { determinado destino turístico. }\end{array}$ & $\begin{array}{l}\text { saneamento de meio fornecido } \\
\text { pelo CMCI este processo não está } \\
\text { sendo feito como deve ser portanto } \\
\text { os membros das associações não se } \\
\text { mostram satisfeitos com a actual } \\
\text { situação do saneamento do meio. }\end{array}$ \\
\hline Vias de Acesso & $\begin{array}{l}\text { As principais vias que dão acesso as associações } \\
\text { agrícolas encontram-se em mau estado apesar de } \\
\text { existirem trilhas que são usadas para a deslocação. A } \\
\text { sinalização (turística e rodoviária) nas associações } \\
\text { mostra-se insatisfatória, visto que, estes subsistemas } \\
\text { mostram-se inexistentes. Os membros das associações } \\
\text { reforçam este fato quando avaliam pela negativa estes } \\
\text { subsistemas, pois não atingem os padrões exigidos } \\
\text { como apresentada por Beni (2002), " a meta é } \\
\text { proporcionar à população local e flutuante condições } \\
\text { de deslocamento rápido, seguro, económico e eficiente, } \\
\text { particularmente para os equipamentos sociais e de } \\
\text { trabalho". }\end{array}$ & $\begin{array}{l}\text { O fato de não terem vias de acesso } \\
\text { em boas condições } \\
\text { consequentemente a escassez de } \\
\text { meios de transportes consideráveis } \\
\text { que permitissem a deslocação às } \\
\text { associações faz com que os } \\
\text { membros avaliassem o sistema de } \\
\text { transporte negativamente. }\end{array}$ \\
\hline Saúde & $\begin{array}{l}\text { Este sistema é avaliado negativamente pois os } \\
\text { membros das associações se deslocam numa longa } \\
\text { distância para procura desse serviço. Também pelo fato } \\
\text { de existir uma parte das associações que não tem } \\
\text { serviço de saúde colocando em perigo a vida dos } \\
\text { membros das associações quando necessitam de forma } \\
\text { urgente, este serviço. Para promover o turismo rural } \\
\text { nas associações há necessidade de se criarem unidades } \\
\text { sanitárias devidamente equipadas assim como fornecer } \\
\text { kits de primeiros socorros que poderão atender não só } \\
\text { os turistas, mas também a comunidade local. }\end{array}$ & $\begin{array}{l}\text { O sistema de saúde } \text { nas } \\
\text { associações agrícolas não é } \\
\text { satisfatório apesar de existirem } \\
\text { algumas associações que tem } \\
\text { unidades sanitárias nas suas } \\
\text { proximidades. }\end{array}$ \\
\hline Educação & $\begin{array}{l}\text { O fato da maioria dos membros das associações terem } \\
\text { o nível de escolaridade básico faz com que a avaliação } \\
\text { desse sistema seja negativa, embora, existem membros } \\
\text { que tem outras formações nas áreas de agricultura, } \\
\text { turismo, pecuária e corte e costura. Deste modo há } \\
\text { necessidade de investir no ensino primário, secundário } \\
\text { e alfabetização adultos. }\end{array}$ & $\begin{array}{l}\text { As associações agrícolas do MI } \\
\text { possuem um sistema educacional } \\
\text { razoável, visto que, este não atende } \\
\text { aos padrões desejáveis apesar de } \\
\text { todas as associações possuírem } \\
\text { escolas primárias nas suas } \\
\text { proximidades onde os membros } \\
\text { das associações podem aproveitar } \\
\text { esses espaços para varias } \\
\text { formações. }\end{array}$ \\
\hline Segurança & $\begin{array}{l}\text { Gollo (2004) afirma que as pessoas costumam } \\
\text { privilegiar a escolha de destino para viajar, levando em } \\
\text { conta aspectos referentes a oferta turística (qualidade } \\
\text { dos serviços, dos equipamentos, originalidade do } \\
\text { produto, condições básicas de infra-estruturas, preços } \\
\text { etc.) e a percepção de segurança. Este não garante de } \\
\text { forma eficaz a segurança dos membros e seus bens } \\
\text { porque regista um índice de furtos dos produtos nas } \\
\text { machambas, o que faz com que este sistema seja } \\
\text { avaliado negativamente, pois, não atinge os padrões de } \\
\text { segurança apresentados por Azevedo (2006). As } \\
\text { associações não apresentam a segurança pública pelo } \\
\text { fato de existência de furtos nas machambas, há falta de }\end{array}$ & $\begin{array}{l}\text { Observou-se que o sistema de } \\
\text { segurança, nas associações } \\
\text { agrícolas, não é satisfatório por } \\
\text { falta de guardas e postos policiais } \\
\text { nos bairros onde estão localizadas } \\
\text { as associações, embora exista } \\
\text { sistema de segurança comunitário. }\end{array}$ \\
\hline
\end{tabular}




\begin{tabular}{|l|l|l|}
\hline & $\begin{array}{l}\text { segurança de saúde e saneamento pela falta de kits de } \\
\text { primeiros socorros e um sistema organizado de } \\
\text { saneamento do meio. }\end{array}$ & \\
\hline
\end{tabular}

Fonte: Adaptado de Mtitu (2018)

Em termos gerais, verificou-se que o MI, no cômputo geral, apresenta uma avaliação negativa em termos de infra-estrutura básica, fato que inibe e continuará a inibir o desenvolvimento agrícola e do turismo rural, reduzindo a capacidade de promoção de iniciativas que visem a diversificação da oferta turística do município e a garantia da produtividade e produção nos dois sectores. A correcta provisão de infra-estrutura é importante para que as unidades de acolhimento nas propriedades de agroturismo possam oferecer, aos visitantes, condições básicas nas actividades e nos momentos de descanso.

\section{d) Comercialização}

A produção no MI destina-se a subsistência das famílias envolvidas e a comercialização em diferentes locais, conforme ilustra a figura 4.

Figura 4. Locais de comercialização dos produtos produzidos no MI

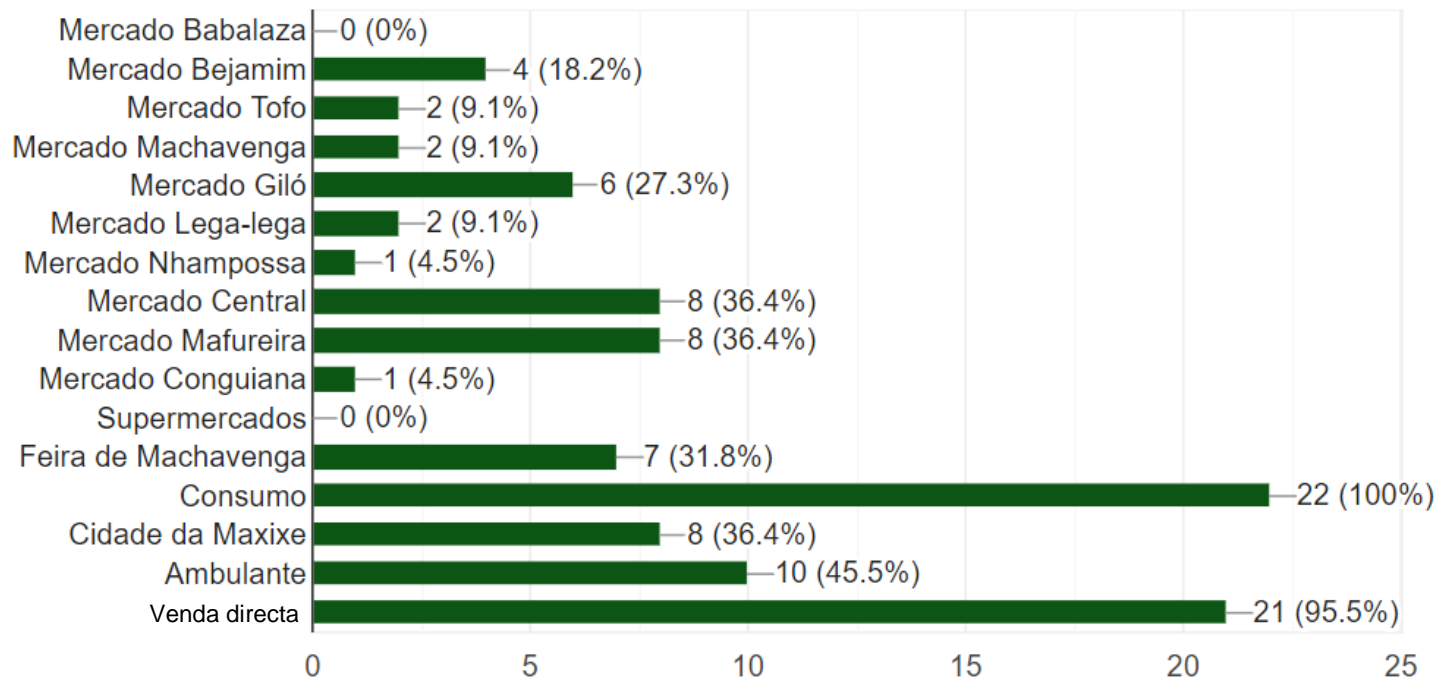

Fonte: Salehe (2018)

Observa-se, na figura 3, que a venda directa no mercado são canais de comercialização utilizados. Apesar de existirem vários supermercados na cidade, estes ainda não comercializam os seus produtos nestes espaços.

No ano de 2019, por meio de um trabalho de extensão e como resultado do processo de investigação e extensão desenvolvido pela ESHTI, foi concebida e operacionalizada a Feira 
Urbana de Inhambane como um espaço alternativo a comercialização, conforme ilustra a figura 5. Este trabalho buscou, igualmente, financiamento para formação dos agricultores em vários domínios e criação de capacidade para melhor apresentação dos produtos/serviços das associações.

Figura 5. Agricultores expondo na Feira Urbana de Inhambane

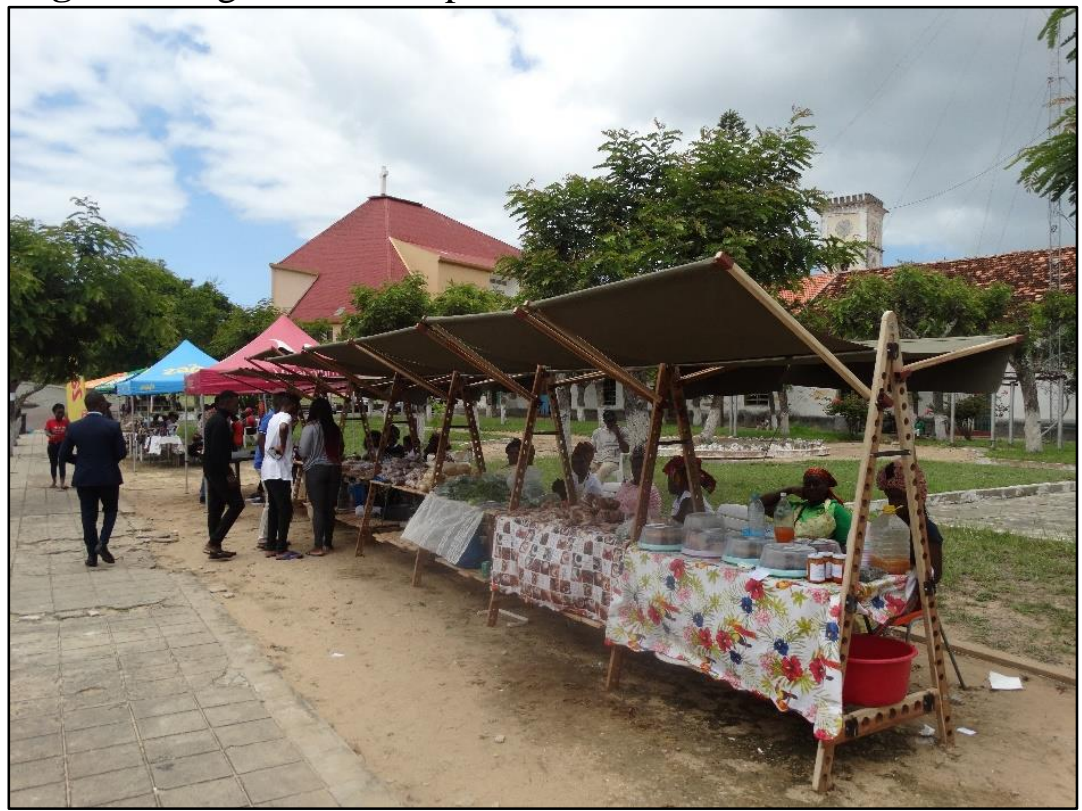

Fonte: Azevedo (2019)

O agroturismo se configura, igualmente, como uma oportunidade adicional para estes poderem vender os seus produtos e ainda aproveitar, por meio da gastronomia local, conforme se testou na Associação Marrambone, conforme ilustra a figura 6.

Figura 6. Excursionistas visitando a Associação agrícola de Marrambone (teste do roteiro turístico)

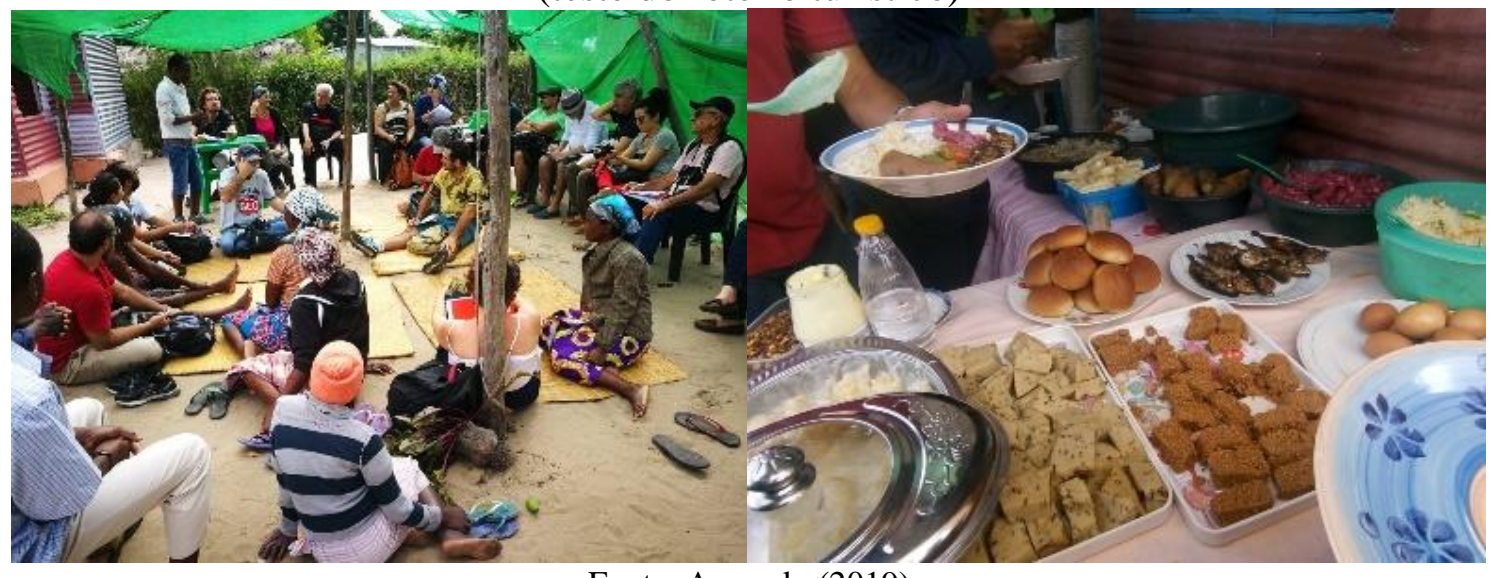

Fonte: Azevedo (2019) 
A experiência permitiu verificar o grau de preparo desta associação para prestar serviços e outros testes em outras associações estão em curso.

Em relação ao uso das tecnologias de informação e comunicação, 94\% informou não realizar a divulgação de suas actividades e produtos por meio das modernas ferramentas, sendo que somente uma o faz, através do Facebook. Esta situação é considerada negativa, visto que, estes canais aproximam a procura (locais, excursionistas e turistas) da oferta de forma mais eficientes.

Espera-se que, com novas abordagens que estão na lógica da economia solidaria, ocorra um incentivo para o aumento da cooperação e associativismo e confiança, e consequentemente poderá haver o incremento na produtividade agrícola dos mesmos, visto que com o incremento da renda, estes poderão adquirir mais insumos para a produção agrícola e para dinamizar outras actividades nas associações.

\section{CONSIDERAÇÕES FINAIS}

Em termos gerais, foi possível identificar o potencial natural e cultural, para que ocorra maior dinamização dos sectores de agricultura e turismo no MI no sentido de se desenvolver o agroturismo. Apesar de ter-se verificado que a organização dos agentes promotores deste desenvolvimento, é ainda insatisfatória.

A integração dos agricultores familiares e da comunidade rural, em geral, no turismo rural que representa uma ligação directa ainda é exígua visto existirem desafios que põem em causa o desenvolvimento das iniciativas de turismo rural neste município, fato que reduz a capacidade de aproveitamento das recursos e/ou oportunidades locais para melhoria do desenvolvimento rural/local. A titulo de exemplo, o fornecimento de pratos típicos aos turistas constitui um aspecto essencial e não só, para a demanda da produção agrícola familiar. Assim, as associações agrícolas que inserirem unidades de alojamento e restauração na sua oferta têm o potencial de constituírem alternativa de mercado para a produção turística que é protagonizada pelo capital internacional.

Conclui-se que há uma oportunidade de estabelecer conexões entre agricultura e turismo, pois é uma maneira das comunidades valorizarem sua cultura e o ambiente rural. Os desafios centrais para a concretização estão relacionados a limitada infra-estrutura de apoio, fraca articulação para o marketing, pouco conhecimento da área hoteleira e limitações, principalmente financeira, para a promoção da oferta. Uma das evidências do potencial 
encontrado é a gastronomia típica das comunidades rurais, o conhecimento local e a própria cultura. Contudo, o potencial agrícola das áreas rurais e a combinação com as características das comunidades rurais não são incorporadas à produção turística pelas associações, abrindose a oportunidades para inserir a filosofia da economia solidária no processo de desenvolvimento agro-turístico neste município.

\section{AGRADECIMENTOS}

O autor agradece ao Mestre Ricardo Pinto e ao Mestre Arlindo Nhacuongue pelas traduções dos resumos para a língua inglesa e francesa, respectivamente. Agradece-se, igualmente, ao Fundo Nacional de Investigação de Moçambique e a Coordenação de Aperfeiçoamento de Pessoal de Nível Superior do Brasil pelo apoio financeiro no âmbito dos dois projectos financiados.

\section{REFERÊNCIAS}

AZEVEDO, F. F.; ALIÓ, M. À.; SILVA, R. P. da. Espacialidade da economia solidária no Brasil. Biblio $3 W$. Revista Bibliográfica de Geografía y Ciencias Sociales. [En línea]. Barcelona: Universidad de Barcelona, 25 de enero de 2016, Vol. XXI, n ${ }^{\circ}$ 1.148. Disponível em: http://www.ub.es/geocrit/b3w-1148.pdf.

AZEVEDO, H. A. M. A; CAMPOS, M. P. Diagnóstico agrícola do município de Inhambane em Moçambique. Revista Sapiência: sociedade, saberes e práticas educacionais, 2016, v5, n. 1, p. $38-56$.

AZEVEDO, H. A. M. de A. Análise da infra-estrutura básica no município de Pemba. (Trabalho de conclusão da cadeira de Relatório dos Estágios apresentado a ESHTI, como exigência parcial para obtenção do grau de Licenciatura em Turismo). Inhambane, 2006.

AZEVEDO, H. A. M. de A. A segurança em territórios turísticos: o caso do município de Inhambane em Moçambique. 2014. $267 \mathrm{f}$. Tese (Doutoramento em Geografia) Universidade Federal de Goiás, Goiânia, 2014.

BARBIERI, C. An importance-performance analysis of the motivations behind agritourism and other farm enterprise developments in Canada. Journal of Rural and Community Development, v. 5, n. 1/2, 2010.

BENI, M. C. Análise Estrutural do Turismo. $7^{\text {a }}$ Edição. São Paulo: Senac, 2012.

BILÉRIO, B.. Papel dos governos (autarquias) locais na consolidação da democracia em Moçambique: 1998-2006: caso do município de Inhambane. In: Conferencia inaugural do IESE - Desafios para a investigação social e econômica em Moçambique, Maputo: 2007. 
CONSELHO MUNICIPAL DA CIDADE DE INHAMBANE. Plano de estrutura do município de Inhambane 2013. Inhambane: CMCI, 2013.

ESPOSTI, R. Agriturismo al bivio? AgriRegioniEuropa, Ancona, ano2, n. 5, jun. 2006.

FRANÇA F., G. Esclarecendo terminologias: as noções de terceiro setor, economia social, economia solidária e economia popular em perspectiva. Revista de desenvolvimento econômico, Salvador, Ano 3, n. 5, p. 52-60, dez. 2001.

GOLLO, G. G.. Segurança \& Turismo: percepções quanto ao aspecto "segurança" de um destino turístico, como forma de mantê-lo atrativo e competitivo. Caxias do Sul - RS. 2004. 100f. Dissertação (Mestrado em Turismo) - Universidade de Caxias do Sul-RS, 2004.

GUZATTI, T. C. O agroturismo como instrumento de desenvolvimento rural; sistematização e análise das estratégias utilizadas para a implantação de um programa de agroturismo nas encostas da serra geral catarinense. Dissertação de Mestrado apresentada ao Programa de Pós-Graduação em Engenharia de Produção da Universidade Federal de Santa Catarina, 2013. Disponível em: https://repositorio.ufsc.br/ handle/123456789/86515.

INSTITUTO NACIONAL DE ESTATÍSTICA. Estatísticas do distrito da Cidade de Inhambane. Maputo: INE, 2010.

INSTITUTO NACIONAL DE PLANEAMENTO FÍSICO. Plano de estrutura da cidade de Inhambane: parte I - análise. Maputo: INPF,1991.

MASCARENHAS, L. B. Economia Popular Solidária. In: Dicionário de políticas públicas / Organizadores: Carmem Lúcia Freitas de Castro, Cynthia Rúbia Braga Gontijo, Antônio Eduardo de Noronha Amabile. Barbacena: EdUEMG, 2012. 242f.

MTITU, T. S. Promoção do turismo rural nas associações agrícolas do município de Inhambane: avaliação da infra-estrutura básica. $67 \mathrm{f}$. Monografia (Licenciatura em Gestão de Mercados Turísticos) - Universidade Eduardo Mondlane, Inhambane, 2018.

NHANTUMBO, Emídio S. Tendências de desenvolvimento do turismo e alterações na ocupação e utilização do espaço no MI. Inhambane: UEM, 2007.

PORTUGUEZ, A. P. Agroturismo e Desenvolvimento regional. 3 ed. Ituiutaba: Barlavento, 2017, 317 p.

SALEHE, S. B. Proposta de um roteiro de agroturismo para a dinamização do turismo rural no município de Inhambane. 2018. 67 f. Projecto de Desenvolvimento (Licenciatura em Gestão de Mercados Turísticos) - Universidade Eduardo Mondlane, Inhambane, 2018.

SINGER, P. Introdução à economia solidária. São Paulo: Editora Fundação Perseu Abramo, 2002.

TEW C. e BARBIERI C. The perceived benefits of agritourism: the provider's perspective. Tourism Management, v. 33, 2012. 
UNIÃO NACIONAL DOS CAMPONESES. Manifesto da UNAC. Maputo: União Nacional dos Camponeses, 2007.

BARROS, V. A. de; DE OLIVEIRA, F. G., «Cooperação e solidariedade em empreendimentos de economia solidária», Laboreal [Online], Volume $15 \mathrm{~N}^{\circ} 1 \mid 2019$, posto online no dia 01 julho 2019, consultado e, 08 Agosto 2021. Disponível em: http://journals.openedition.org/laboreal/986; DOI: https://doi.org/10.4000/laboreal.986

ZANDONADI, B. M.; FREIRE, A. L. Agroturismo: cultura e identidade agregando renda no espaço rural. Revista de Turismo Contemporâneo, Natal, v.4, n.1, p. 23-44, jan./jun. 2016.

Recebido em 12 de setembro de 2021

Aprovado em 27 de dezembro de 2021

Publicado em 07 de fevereiro de 2022. 